\section{Extinction of human eyelid conditioning as a function of components of a masking procedure ${ }^{1}$}

RONALD S. KESSLER, ${ }^{2}$ CARL D. WILLIAMS, and NEIL SCHNEIDERMAN, University of Miami, Coral Gables, Fla. 33124

Eyelid conditioning and extinction procedures were embedded in a masking probability learning task. On non-CS trials interspersed with extinction trials, a 100\% masking $(100 \% M)$ group received the US along with the masking stimuli, whereas a masking + free-shock $(M+F S)$ group received US-alone presentations. A control (C) group received the same stimuli as did Group $100 \% M$ but with neutral instructions. Group 100\% $M$ revealed more, but Group $M+F S$ revealed less, resistance to extinction than did Group $C$. Only the $M+F S$ group extinguished completely.

Spence (1966a) suggested that the extinction performance of humans in eyelid classical conditioning is influenced importantly by cognitive factors. According to Spence, human Ss readily discriminate extinction from acquisition as soon as the US is discontinued during extinction. Once this discrimination is made, $S$ rapidly develops a set not to respond to the CS.

In order to control or eliminate the cognitive set not to respond, Spence and his associates (Spence, 1966a, b; Spence, Homzie, \& Rutledge, 1964) used a procedure intended to prevent $S s$ from discriminating the transition from acquisition to extinction. Basically, this consisted of embedding the conditioning and extinction procedures in the context of a masking probability-learning task. Although the instructional set and superimposition of the guessing task on the conditioning situation may have distracted the Ss from the true purpose of the experiment, other considerations must also be taken into account before the increase in resistance to extinction observed by manipulation of cognitive factors. The purpose of the present experiment was to examine some of the variables that may have contributed to the increased resistance to extinction obtained in the Spence masking paradigm.

$$
\text { METHOD }
$$

Each of $180 \mathrm{Ss}$ from introductory psychology classes was seated in a lighted room. The eyeblink transduction apparatus consisted of a microtorque potentiometer mechanically coupled to the lid. In Spence can be attributed exclusively to the addition to the eyeblink apparatus, each $S$ also wore a set of earphones through which the $1,000-\mathrm{Hz}, 58-\mathrm{dB}$ SPL tone CS was delivered. The US was a .6-mA, 100 -msec-duration infraorbital shock delivered by a constant amperage ac shock generator. Three 25-W bulbs were located $6 \mathrm{ft}$ in front of $S$. The center bulb was red and the outside two were blue. A two-way switch was mounted on a board placed across the arms of S's chair. Programming and recording equipment, including an Offner dynograph run at a chart speed of $100 \mathrm{~mm} / \mathrm{sec}$, was placed in a separate room.

Each $\mathrm{S}$ was given three CS-alone trials followed by 24 CS-US pairings in terspersed with 24 trials in which only the red warning signal and the blue information lights were presented. In extinction, the Ss received 37 extinction trials interspersed with 37 trials in which the US but not the CS was presented. A 4-min rest period preceded the last $12 \mathrm{CS}$ and last $12 \mathrm{US}$ trials.

In two of the three treatment groups (100\% masking; masking + free shock), the conditioning and extinction sessions were embedded in a masking situation similar to that described by Spence (1966a). The Ss in these groups were told that the experiment was concerned with the effects of stimulus distraction on a problem-solving situation involving the prediction of which of the blue bulbs to the right or left of the red one would light up following the onset of the red light. The Ss in the third (control) group were exposed to the same sequence of red and blue lights given to the two masked groups, but no mention of the lights was made and the Ss were not asked to guess.

The types of trials received by each group during acquisition and extinction are shown in Table 1. Table 1 indicates that during acquisition, half of the trials (upper line in each group) were conditioning trials, and half of the trials (lower line in each group) were nonconditioning trials in which both the CS and US were omitted. It can also be seen that the acquisition procedures were identical in the $100 \%$ masking and in the masking + free-shock conditions during acquisition, but that during the $50 \%$ of trials in extinction in which the CS was not presented, the two groups differed markedly from each other in the stimuli they received.

For half of the Ss (warning signal delay Ss) in the three groups, the red warning signal, when it occurred, was on for $1,000 \mathrm{msec}$ and offset simultaneously with the onset of the 600 -msec-duration CS. For the other half of each group (warning signal trace Ss), the red warning signal light was on for $500 \mathrm{msec}$ followed $500 \mathrm{msec}$ after warning-signal termination by the 600-msec-duration CS. Since the US onset $500 \mathrm{msec}$ after CS onset and offset simultaneously with the CS, the CS-US interval in each group was $500 \mathrm{msec}$ and the warning signal-US interval was $1,500 \mathrm{msec}$. Four hundred milliseconds after CS and US termination, one of the blue bulbs lighted for $1,000 \mathrm{msec}$.

\section{RESULTS}

The percentages of CRs for each group during each stage of training are shown in Fig. 1. An analysis of variance conducted upon the arc sine transforms of individual per cent CRs making up this figure failed to reveal reliable differences among groups during acquisition $[F(2,168)=1.42$, $\mathrm{p}>.05$ ] but did reveal reliable differences during first extinction $[F(2,168)=6.03$, $\mathrm{p}<.003]$ and during second extinction $[F(2,168)=4.06, p<.019]$. Postanalysis Duncan's new multiple-range tests applied with alpha $=.05$ to the differences between group means indicated that (a) the masking + free-shock group significantly differed from the control group as well as from the $100 \%$ masking group during both first and second extinction, and (b) the $100 \%$ masking group differed significantly from the control group during first but not during second extinction.
Table 1

Stimulus Events During Experiment for the Three Groups

\begin{tabular}{|c|c|c|c|c|c|c|c|c|c|c|}
\hline \multirow[b]{2}{*}{ Group } & \multicolumn{5}{|c|}{ Acquisition } & \multicolumn{5}{|c|}{ First and Second Extinction } \\
\hline & $\begin{array}{c}\text { Red } \\
\text { Light }\end{array}$ & $\begin{array}{l}\text { Toggle } \\
\text { Switch }\end{array}$ & Tone & Shock & $\begin{array}{l}\text { Blue } \\
\text { Light }\end{array}$ & $\begin{array}{c}\text { Red } \\
\text { Light }\end{array}$ & $\begin{array}{l}\text { Toggle } \\
\text { Switch }\end{array}$ & Tone & Shock & $\begin{array}{l}\text { Blue } \\
\text { Light }\end{array}$ \\
\hline Control & + & - & + & + & $\begin{array}{l}+ \\
+\end{array}$ & $\begin{array}{l}+ \\
+\end{array}$ & $\overline{-}$ & + & $\overline{+}$ & $\begin{array}{l}+ \\
+\end{array}$ \\
\hline $100 \%$ Masking & $\begin{array}{l}+ \\
+\end{array}$ & $\begin{array}{l}+ \\
+\end{array}$ & + & $\begin{array}{l}+ \\
-\end{array}$ & $\begin{array}{l}+ \\
+\end{array}$ & $\begin{array}{l}+ \\
+\end{array}$ & $\begin{array}{l}+ \\
+\end{array}$ & $\begin{array}{l}+ \\
-\end{array}$ & + & $\begin{array}{l}+ \\
+\end{array}$ \\
\hline Masking + Free Shock & $\begin{array}{l}+ \\
+\end{array}$ & $\begin{array}{l}+ \\
+\end{array}$ & + & + & + & $\begin{array}{l}+ \\
-\end{array}$ & $\begin{array}{l}+ \\
-\end{array}$ & $\begin{array}{l}+ \\
-\end{array}$ & - & + \\
\hline
\end{tabular}

$+=$ present; $-=a b \operatorname{sent}$ 


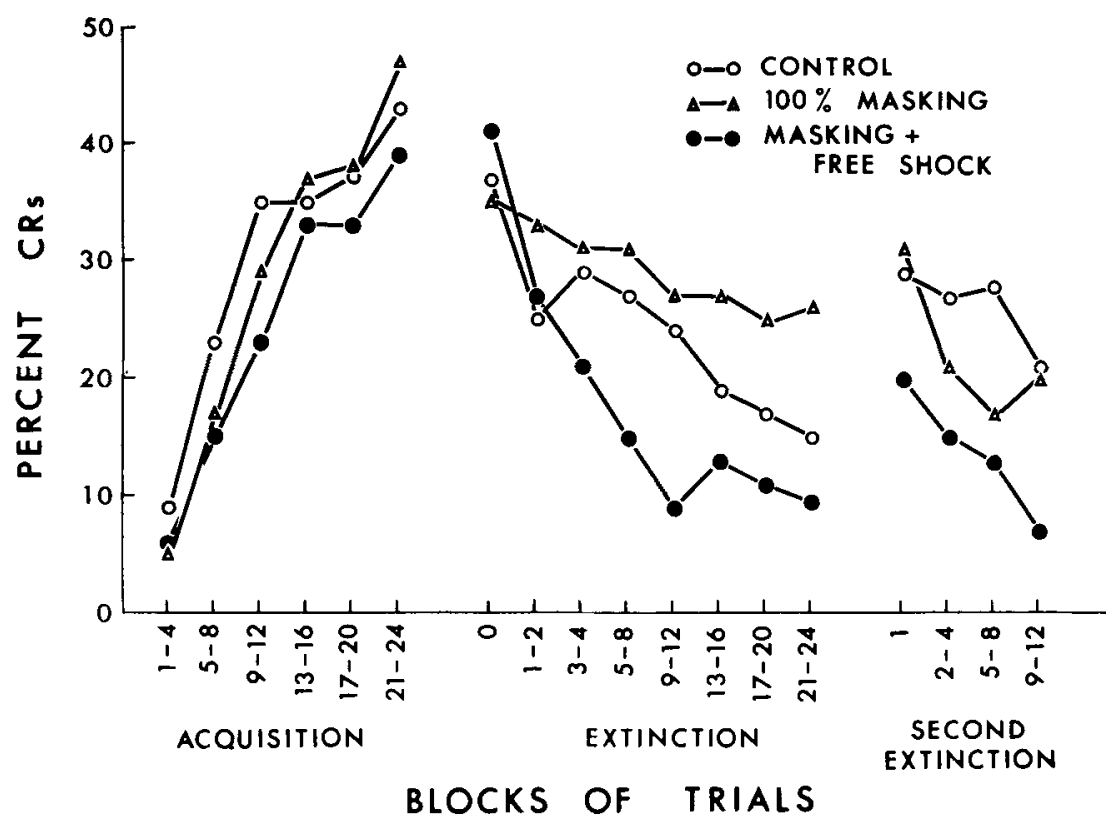

A repeated-measures analysis of variance conducted on the block means of all 180 Ss indicated that mean responses varied reliably over trial blocks during acquisition $[\mathrm{F}(1,170)=159.59, \mathrm{p}<.001]$ and during first extinction $[F(1,170)=30.47$, $\mathrm{p}<.001]$ but not during second extinction $[F(1,170)=.44, p>.05]$. Similar repeated-measures analyses of variance comparing performance on the first acquisition block and on the final second extinction block showed reliable differences for the control group $[F(1,56)=13.60, p<.001]$ and for the $100 \%$ masking group $[\mathrm{F}(1,56)=11.64$, $\mathrm{p}<.001]$ but not for the masking + free-shock group $[F(1,56)=.62, p>.05]$, indicating that extinction was not complete for either the control group or the $100 \%$ masking group. A similar analysis of variance comparing performance on the last trial of first extinction and the first trial of second extinction revealed reliable differences $[F(1,170)=9.91, p<.002]$, confirming the occurrence of spontaneous recovery.

\section{DISCUSSION}

The chief finding of the experiment was that the $100 \%$ masking group revealed more and the masking + free-shock group less resistance to extinction than did the control group. In extinction, only the masking + free-shock group received US alone presentations on nonCS trials. In contrast, the other groups received a warning signal, US, information light sequence on such trials. Consequently, the response decrement in the masking + free-shock group must have been due to either the US-alone presentations or to Ss receiving 50\% fewer warning signals.

The present finding that "free shocks" facilitated rapid extinction is consistent with Azrin \& Holz's (1966) summary of a wide and varied literature indicating that such shocks tend to suppress ongoing activity. One explanation of Spence's (1966b) finding that US-alone trials retarded rather than facilitated extinction is that his extinction results were due to the associative pairing of the warning signal with the US.

Together, the "free shock" and associative pairings of warning signal and shock explanations reasonably account for most of the differences found among groups. The remaining differences between the control and $100 \%$ masking group were significant only during the first extinction session but were not reliable when examined over the second extinction
Fig. 1. Percentages of CRs for each group during blocks of trials in acquisition and extinction.

period. Although it is conceivable that instructional set accounts for the remaining differences, it is alternatively possible that the chaining effects of the toggle-switch response accounted for the increased resistance to extinction. In any event, the present finding that the control group did not extinguish completely, even after 36 extinction trials, indicates that marked resistance to extinction of human eyelid conditioning is possible in the absence of masking instructions.

The findings of the present experiment do not, of course, rule out instructional set as a variable that increases resistance to extinction. These findings also do not preclude the possibility that masking reduces S's ability to discriminate the transition from acquisition to extinction. Furthermore, the experimental findings of Prokasy \& Kumpfer (1969) emphasize the utility of other kinds of masking procedures in eyelid conditioning. The present findings do, however, indicate that instructional set does not play the preeminent role in increasing resistance to extinction within the Spence masking situation.

\section{REFERENCES}

AZRIN, N., \& HOLZ, R. Punishment. In W. Honig (Ed.), Operant behavior: Areas of research and application. New York: Appleton-Century-Crofts, 1967. Pp. 380-447.

PROKASY, W. F., \& KUMPFER, K. L. One- and two-operator versions of a two-phase model applied to the performances of $V_{s}$ and $C s$ in human eyelid conditioning. Joumal of Experimental Psychology, 1969, 80, 231-236. SPENCE, K. W. Cognitive and drive factors in the extinction of the conditioned eye blink in human subjects. Psychological Review, 1966a, 73, 445-458.

SPENCE, K. W. Extinction of the human eyelid $C R$ as a function of presence or absence of the UCS during extinction. Journal of Experimental Psychology, 1966b, 71, 642-648.

SPENCE, K. W., HOMZIE, M. J., \& RUTLEDGE, E. F. Extinction of the human eyelid $C R$ as a function of the discriminability of the change from acquisition to extinction. Journal of Experimental Psychology, 1964, 67, 545-552.

\section{NOTES}

1. Supported by NASA Grant NGR 10-007-010.

2. Now at Lynchburg College, Virginia. 